\title{
Use of Psychoactive Substances during COVID-19 in Republic of North Macedonia
}

\author{
Elena Kjosevska ${ }^{1,2}$, Sanja Prosheva ${ }^{1}$ \\ ${ }^{1}$ Institute of Public Health of the Republic of North Macedonia, Skopje, Republic of North Macedonia \\ ${ }^{2}$ Faculty of Medicine, University "St. Cyril and Methodius", Skopje, Republic of North Macedonia \\ Corresponding Author: E. Kjosevska
}

DOI: https://doi.org/10.52403/ijhsr.20220302

\begin{abstract}
Introduction: COVID-19 pandemic is the biggest health crisis of our time. The aim of paper is to present the results related to the use of the illicit drugs due to the COVID-19 pandemic, from the perspective of users.

Materials and Methods: It was used online survey as a cross-sectional study from the European Monitoring Centre for Drugs and Drug Addiction, for drug users aged 18 years or older, in the 12 months prior to the survey, between March and April 2021. The main instrument was EWSD questionnaire structured in 8 modules. Descriptive and analytical statistical methods were used.

Results: The total number of respondents was $336.59 \%$ were male, $35 \%$ female. $73 \%$ were young people between 18 to 34 years old and $26 \%$ were from 35 to 70 years old. The last year prevalence of drug use: $90 \%$ answered that they used cannabis, $76 \%$ answered that they used herbal cannabis to reduce stress, around half of them said that they use to get high, to improve sleep or to socialize. The most commonly reported setting for drug use was home, mentioned by around $77 \%$ of the respondents.

Discussion: At the time when the research has been conducted, country was facing the big wave of the COVID-19 crisis, with implemented restrictions, lockdowns and reduced contacts. That fact can explain the decreased number of the use of ecstasy and cocaine powder and the increased use of herbal cannabis at home.
\end{abstract}

Conclusions: COVID-19 had a huge impact on the use of drugs.

Key Words: use, psychoactive substances, COVID-19, Republic of North Macedonia

\section{INTRODUCTION}

COVID-19 pandemic is the biggest health crisis of our time. There are many people fighting the COVID-19 with all their might, but people which use drugs faced many challenges during isolations and lockdowns. In the past, Republic of North Macedonia (RNM) used the General Population Survey (GPS) to monitor the drug situation and trends with the consumption of drugs from the general population and to obtain information on patterns of use of illicit drugs into the country [1].Thanks to the European Monitoring Centre for Drug and Drug
Addiction (EMCDDA), RNM had a chance to conduct a web survey on drugs [2] in order to collect information on the amounts of drugs used by different groups of drug users. This web-based survey was a useful tool for collecting information on patterns of drug use from a wider range of people who use illicit drugs. Compared to the GPS, this survey was quickly, cheaply and safer way due to the time of pandemic.

RNM started the implementation of the EWSD for the first time in 2021. This survey was covered and supported by the EMCDDA IPA7 project. The Institute of Public Health of the Republic of North 
Macedonia (IPH) was the implementer of this European web survey on drugs, with support from the Ministry of Health of the RNM. At the time when the research was conducted, many European countries were experiencing COVID-19-related lockdown or restrictions. It was the same situation in our country with implemented restrictions, lockdowns and reduced contacts. Disco bars, coffee bars, restaurants were fully closed or with limited working hours [3].

The overall aim of the paper is to present the results related to the use (consumption) of the illicit drugs cannabis, cocaine, ecstasy, amphetamines, methamphetamines, heroin and new psychoactive substances (NPS) due to the COVID-19 pandemic, from the perspective of users.

\section{MATERIALS AND METHODS}

European Web Survey on Drugs in RNM was designed as a cross-sectional study. The data collection was trough online survey (different sources of web pages and Facebook pages with paid ad). Participation in this project was completely voluntary. The survey was anonymous. No IP addresses were stored and no tokens were used.

\section{Instrument}

The main instrument for the survey was the EWSD - English master questionnaire translated in Macedonian and Albanian language. An on-line questionnaire can be completed independently, anonymously, through the software Lime Survey, managed by the EMCDDA.

The questionnaire was structured in 8 modules: A bit about you, cannabis module, cocaine module, ecstasy/MDMA, amphetamine, methamphetamine, heroin module and NPS module. The questions collect data about: socio-demographics characteristics, drug using patterns, access to treatment and access to drugs (amounts usually bought and prices paid). Bearing in mind that the questionnaire was applied between March and April 2021 and that the questions asked related to the period of the previous 12 months, in a pandemic context, a question about changes in consumption due to the COVID-19 pandemic was included in each module.

\section{Cognitive interviews}

For the purpose of testing the comprehensibility and logic of translated questionnaire, there were arranged cognitive interviews with 10 respondents representing different target sub-populations of people who use drugs ( 3 cannabis users, 2 cocaine users, 2 ecstasy users, 1 amphetamine user, 1 methamphetamine user and 1 heroin user).

\section{Respondents}

The web-based survey targeted people aged over 18 who have used one or more drugs over the last 12 months: cannabis (hashish or marijuana), cocaine, ecstasy/MDMA, amphetamine, methamphetamine, heroin or any 'NPS'.

Respondents were self-selected and country recruitment strategies consisted of a mixture of social media campaigns, press releases and contacts with drug-related networks.

\section{Trainings for data collection}

Representative from the Macedonian team participated in web-based trainings (cognitive interviewing - for testing the questionnaire, using Lime Survey, and how to use social media to recruit people to fill in the survey) that was organized by the EMCDDA team in the period -end of June and September 2020.

\section{Recruitment plan}

The recruitment plan was created before the survey was launched. In general, the promotion plan was implemented with few adaptations and few exceptions.

There were used several promotion strategies in order to ensure a larger number of answered questionnaires, namely:

- Collaboration with NGOs 
- Collaboration with Centers for rehabilitation

- Spread info on relevant pages

- Interaction with a client via inside groups

- Cannabis legalization initiatives

- Facebook page and Facebook ads.

\section{Statistical analysis}

Online questionnaires were fulfilled and collected with the software Lime Survey. The data obtained during the research were statistically processed using Excel. Numerical series were analyzed using central tendency measures (mean, median, minimum values, maximum values, interactive rankings), as well as dispersion measure (standard deviation). The analysis of the attributive (qualitative) series was done by determining the proportions and rates. The graphs were produced in $\mathrm{R}$ using RStudio and they are simple relative frequencies.

\section{RESULT}

Altogether more than 2900 people visited the survey start page of which about 674 agreed to participate in the survey, resulting with 354 valid responses. From the total number of respondents $59 \%$ were male, $35 \%$ female, $1 \%$ non-binary and $5 \%$ of the respondents preferred not to say the gender. Regarding the participants' age, $73 \%$ were young people between 18 to 34 years old and $26 \%$ were from 35 to 70 years old (mean=30.0, median 28.0, mode $=21$,
Std.Dev.=8,63, range 52, $\max =70, \min =18$ ). Almost all of the respondents reported that they live in a town (52\% in the capitalSkopje and $43 \%$ in other town across the country). Only 4\% from the respondents live in a village. Regarding the sociodemographic characteristic of the participants, most of them $-71 \%$, completed or attendant but not completed higher education (university or equivalent), $28 \%$ were with secondary education (most of them completed) and only $1 \%$ of the respondents completed primary education. More than half of the respondents $(55 \%)$ were full-time employed, $19 \%$ were students (some of them employed) and 8\% of the respondents were unemployed or were on a social support. Average income per month after tax was 15.000 denars or more for about $60 \%$ of the respondents, $17 \%$ reported income in less than 3000 denars and others $22 \%$ of respondents had income between 15.000 and 3.000 denars per month.

Regarding the questions about the last year prevalence of the drug use, from the total number of respondents 336, 90\% answered that they used cannabis in the last 12 months, $41 \%$ used cocaine, 35\% used amphetamine, $6 \%$ used methamphetamine, $30 \%$ used ecstasy/MDMA, 7\% LSD, 6\% used heroin and $23 \%$ used NPS. Similar like cannabis, alcohol and tobacco use are high on the list, with $92 \%$ use of alcohol and $87 \%$ use of tobacco, between the drug users (Figure 1).

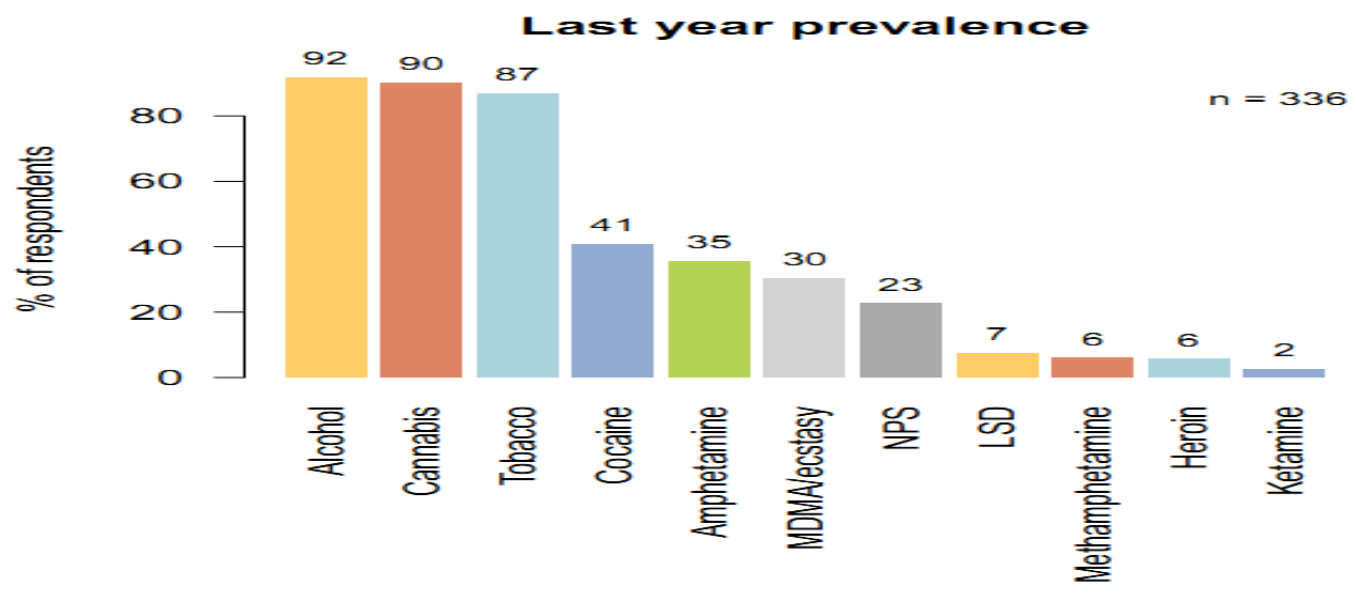

Figure 1. Last year prevalence of drug use in the Republic of North Macedonia 
We can see that the most used drug in our country is cannabis. Regarding to that, on the question - In the last 12 months, why did you use herbal cannabis? $-76 \%$ of the current users answered that they used herbal cannabis to reduce stress or to relax, around half of the users said that they use herbal cannabis to get high/for fun, to improve sleep or to socialize. Only $10 \%$ of the current users answered that they use herbal cannabis out of curiosity/ to experiment (Figure 2).

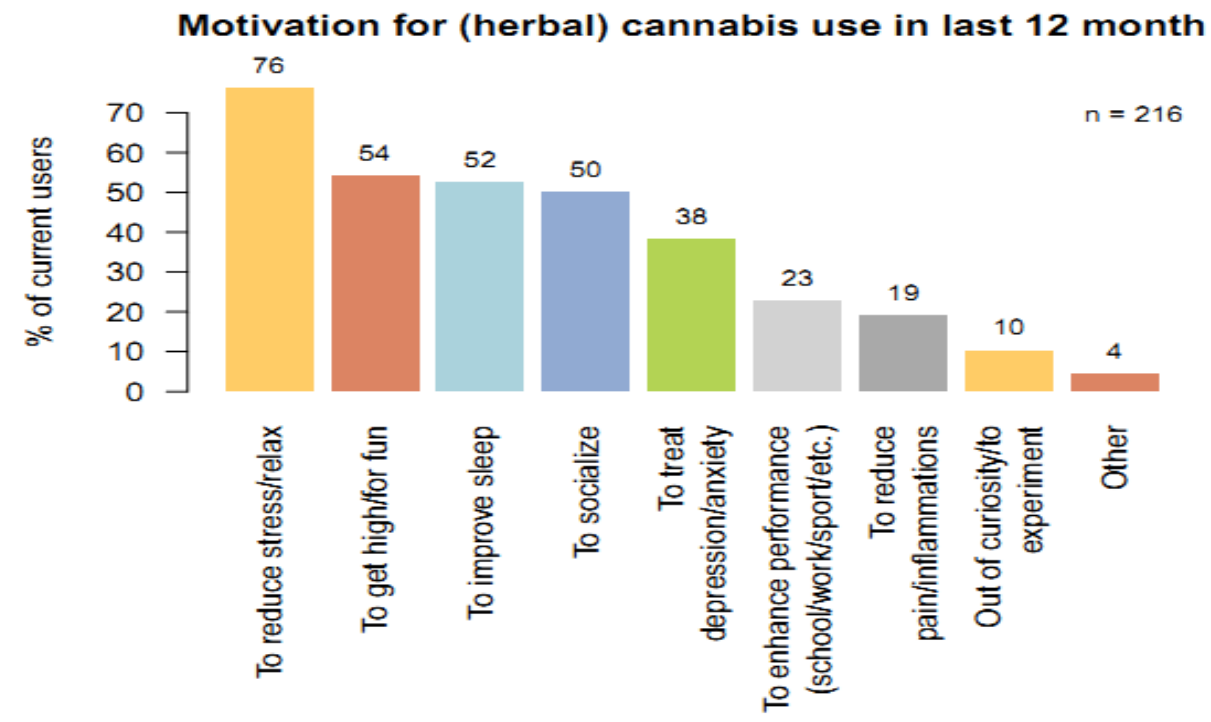

Figure 2. Motivation for herbal cannabis use in the last 12 month in Republic of North Macedonia

On the question - To what extent do you agree or disagree with the following statement: "Taking cannabis should be legal" - $77 \%$ from all the drug users answered that they strongly agree with this statement, $14 \%$ somewhat agree, $6 \%$ either agree or disagree, $1 \%$ somewhat disagree and $2 \%$ strongly disagree.

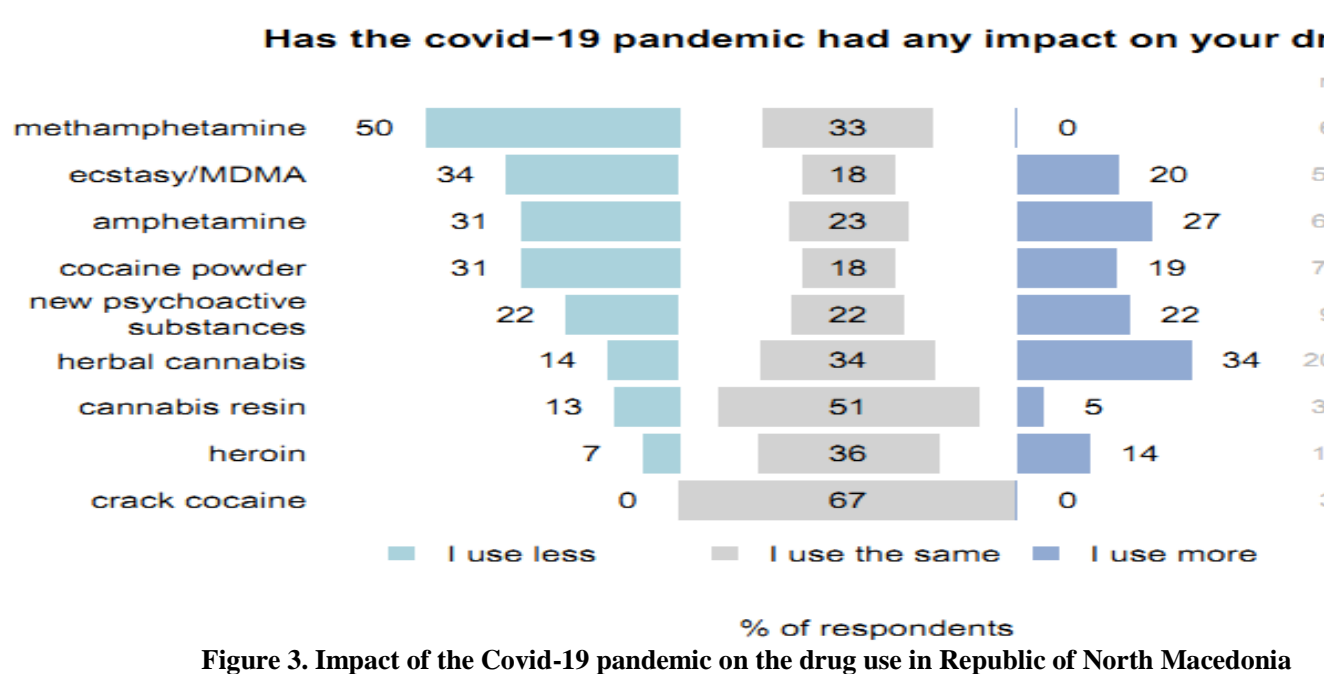

Because the research was conducted due to the COVID-19 pandemic, the main question in each module was: Has the COVID-19 pandemic had any impact on your use of drugs? Regarding this question, the most used drug due to COVID-19 restrictions was herbal cannabis. Same number of participants answered that they used same or more herbal cannabis-34\%. Ecstasy, methamphetamine, amphetamine and cocaine powder were used less due to the COVID-19 restrictions. Majority of the 
crack cocaine and cannabis resin users reported no change in use due to the pandemic (Figure 3).

The most commonly reported setting for drug use in the last 12 months was at home, mentioned by around three quarters-
$77 \%$ of the respondents, and followed by the public place (street, park etc.) with $54 \%$. Drugs were used in a club/bar and on a music festival or party, by $39 \%$ of the respondents. (Figure 4)

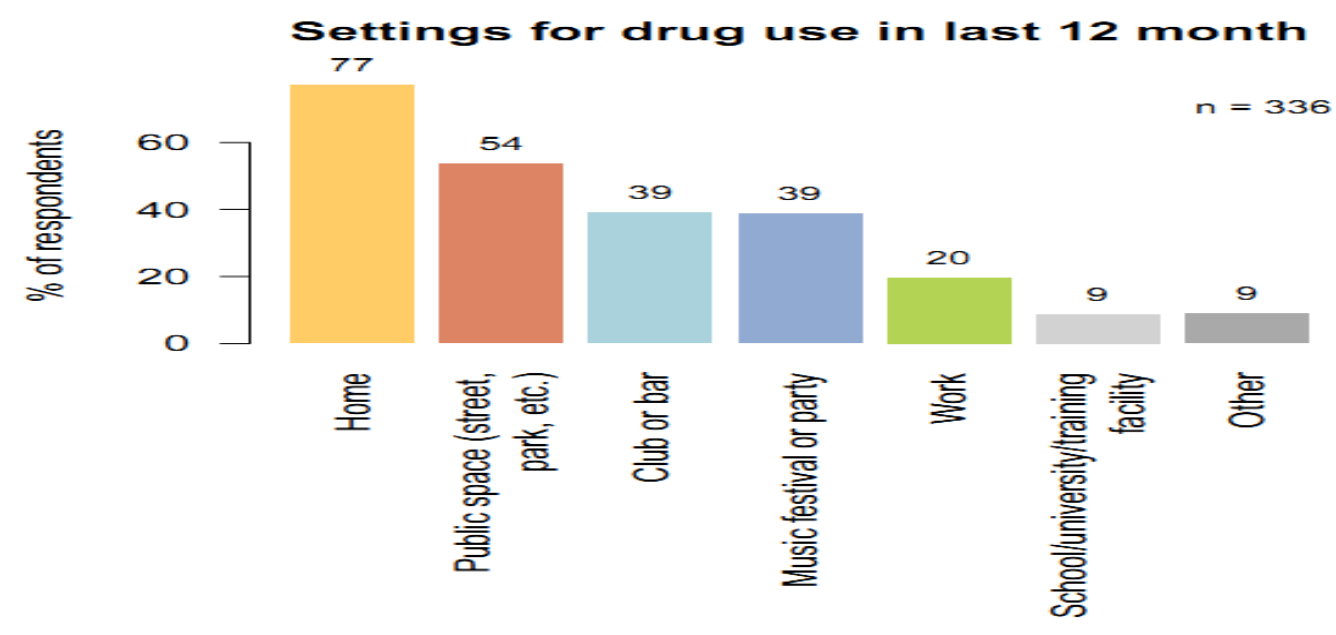

Figure 4. Settings for drug use in last 12 month in Republic of North Macedonia

\section{DISCUSSION}

Globally, on 9 February 2022, there have been $399,600,607$ confirmed cases of COVID-19 in the world, including 5,757,562 deaths, reported to WHO [4]. On the same day, in RNM, there have been 282,147 confirmed cases of COVID-19, including 8,658 deaths, from the beginning of the pandemic [5]. From the numbers we can see how serious the situation with the pandemic is and that the whole world is affected with the crisis. People who use drugs are at increased risk of exposure to the virus that causes COVID-19. Centers for Disease Control and Prevention (CDC) explain that drug use can have serious effects on the body. For example:

- The use of opioids can cause slow breathing, and can even result in ineffective breathing, which can lead to decreased oxygen in the blood, brain damage, or death.

- The use of stimulants, such as cocaine, amphetamine, and methamphetamine, can cause acute health problems such as stroke, heart attacks, abnormal heart rhythm, and seizures, as well as more chronic conditions, such as heart or lung damage.

- The use of drugs by smoking or vaping (for example, heroin, crack cocaine, marijuana) can make chronic obstructive pulmonary disease (COPD), asthma, and other lung conditions worse.

- Other conditions that affect the immune response, such as HIV, are more common among people who use drugs, especially among those who inject drugs [6].

At the time when the EWSD research was conducted, our country was facing the big wave of the COVID-19 crisis, with implemented restrictions, lockdowns and reduced contacts. Disco bars, coffee bars, restaurants were fully closed or with limited working hours. That fact can explain the decreased number of the use of ecstasy and cocaine powder on one hand, and on other hand, the increased use of herbal cannabis.

In addition, the restrictions and lockdowns can explain the huge number of drug users who report that the most commonly reported setting for drug use in the last 12 months was the home and on the 
other side, club/bar, music festival and parties were reported as places where drug was used less. In that period of restrictions, people spent most of their time at home with no possibility to go out or to go in disco and to party.

Due to the COVID-19 restrictions most of the people felt stressed, anxious and depressed, scared for their health and for the health of the closed family members. Herbal cannabis gives an effect of relaxation, opposite from the effects of the use of cocaine and ecstasy, so that is one of the main explanations for the motivation for the use of herbal cannabis.

If we compare the data from the Macedonian research, with the data from the Western Balkan countries, and the data from the EU countries, we can notice similarity. Most of the countries that participated in the research, answered that cannabis is the most common used drug. Similar like Macedonian, responses from Western Balkan - 64\% and from EU countries $78 \%$, suggest that herbal cannabis is taken to reduce stress or to relax $[7,8]$.

Similar like in the GPS [1], prevalence of taking illicit drugs among young people aged up to 34 , is higher than amongst all adults.

The most recent data on drug use among students came from the international ESPAD report 2019 and reported that drug use prevalence among sixteen years old students in Republic of North Macedonia was around half and lower than the European average in the case of all drugs used and that is the most notable fact.

The data from all ESPAD studies carried out in North Macedonia (1999, 2008, 2015 and 2019) indicate that the level of lifetime-cannabis use among 15-16 years old students wasn't significantly different, there was just a very slight increase over the years $(4.5 \%$ in $1999,5.5 \%$ in $2008,5 \%$ in 2015 and $6.1 \%$ in 2019) [9]. However, the risk for increasing the use of drugs due to the COVID-19 and all consequences on student's mental health is very high in the future.
Regarding the education of the participants, most of them $-71 \%$, completed or attendant higher education (university or equivalent) and only $1 \%$ of the respondents completed primary education. In correlation with the education, more than half of the respondents were full-time employed with average income per month of 15.000 denars. This data corresponds to the type of drug used by the respondents-most used drug was cannabis. In addition, the percentage of cocaine users is high, which indicates the fact that people who have a good status in society, as well as sufficient income, use these types of drugs.

\section{CONCLUSION}

COVID-19 had a huge impact on the use of drugs, with both, increasing and decreasing in their use. EWSD is a relatively timely and inexpensive monitoring tool that has capacity to capture recent developments and drug market changes from the perspective of people who use drugs. Users found that they used more herbal cannabis than in the period before COVID-19. The socio-economic conditions in the time of COVID-19 can lead to even greater use, which according to previous experiences and knowledge in the world leads to the use of other types of drugs (heroin, cocaine, NPS, etc.). Therefore, measures are needed that would prevent that trend of deteriorating conditions. In that sense, in order to cover a larger number of drug users with the Addiction Prevention Programs, it is necessary to provide more funds for the collection of excise duties on alcohol, beer and cigarettes, as well as the production of cannabis. It is also necessary to increase and improve the education at an early age of the beneficiaries in order to give up and be accepted by the institutions of the system in the country in order for their rehabilitation and resocialization. The operation of these programs should contribute to reducing the health, social and economic consequences of drug use at the individual, local and community level by implementing a set of activities that include 
sterile injection equipment sharing, condom handling, education and counseling, HIV/AIDS testing, as well as services from various types of professionals - field workers, medical staff, social workers, psychologists and lawyers [9].

\section{Funding}

This research has a financial support by the European Monitoring Centre for Drugs and Drug Addiction (EMCDDA).

\section{Conflict of Interest}

The Authors declares that there is no conflict of interest.

\section{Acknowledgement: None}

\section{Ethical Approval: Approved}

\section{REFERENCES}

1. Onceva S., Kjosevska E., Stefanovska Velikj V., Ivanov Zafirova B. Use of psychoactive substances among the general population in the Republic of Macedonia: 2017: Skopje: Institute of public health of the Republic of Macedonia, 2017. $264 \mathrm{p}$ Research report No1

2. European Monitoring Centre for Drugs and Drug Addiction. European Web Survey on Drugs.[Internet]. 2021. Available from: https://www.emcdda.europa.eu/topics/europ ean-web-survey-on-drugs_en Accessed: Feb 82022

3. Ministry of Health of the Republic of North Macedonia. Corona-virus. [Internet]. 2022. Available from: http://zdravstvo.gov.mk/korona-virus/.

Accessed: Feb 92022

4. WHO Coronavirus (COVID-19) Dashboard. [Internet]. 2022. Available from: https://covid19.who.int/ Accessed: Feb 10 2022

5. Institute of Public Health of the Republic of North Macedonia.COVID-19. [Internet].
2022. Available from: https://www.iph.mk/COVID-19-9-2-2022/ Accessed: Feb 102022

6. Centers for Disease Control and Prevention. COVID-19 and People at Increased Risk. [Internet]. 2022. Available from: https://www.cdc.gov/drugoverdose/resource s/covid-drugs-QA.html Accessed: Feb 10 2022

7. European Monitoring Center for Drugs and Drug Addiction. European Web Survey on Drugs 2021: Top-level findings in the Western Balkans. Available from: https://www.emcdda.europa.eu/publications /data-fact-sheets/european-web-surveydrugs-2021-top-level-findings-ipa7_en Accessed: Feb 102022

8. European Monitoring Center for Drugs and Drug Addiction. European Web Survey on Drugs 2021: Top-level findings, 21 EU countries and Switzerland. [Internet]. 2022. Available from: https://www.emcdda.europa.eu/publications /data-fact-sheets/european-web-surveydrugs-2021-top-level-findings-eu-21switzerland_en Accessed: Feb 102022

9. ESPAD Group. ESPAD Report 2019. Results from the European School Survey Project on Alcohol and Other Drugs. EMCDDA Joint Publications, Publications Office of the European Union, Luxembourg, 2020. [Internet]. 2020. Available from: http://www.espad.org/sites/espad.org/files/2 020.3878_EN_04.pdf Accessed: Feb 92022

10. Dekov V. The future of harm reduction programs in Macedonia. Analysis of the activities and budgets of the harm reduction programs. Skopje, HOPS, 2015.

How to cite this article: Elena Kjosevska, Sanja Prosheva. Use of psychoactive substances during COVID-19 in Republic of North Macedonia. Int J Health Sci Res. 2022; 12(3):11-17. DOI: https://doi.org/10.52403/ ijhsr.20220302 